\title{
PERAN KEPUASAN PELANGGAN MEMEDIASI PENGARUH PERSEPSI HARGA TERHADAP LOYALITAS PELANGGAN
}

\author{
I Putu Eka Astra Prasada ${ }^{1}$ \\ Ni Wayan Ekawati² \\ ${ }^{1,2}$ Fakultas Ekonomi dan Bisnis Universitas Udayana (Unud), Bali, Indonesia \\ e-mail: ekaastra18@gmail.com
}

\begin{abstract}
ABSTRAK
Loyalitas pelanggan merupakan bentuk kesetiaan pelanggan untuk setia atau terus menggunakan produk atau jasa layanan dari perusahaan yang sama di masa yang akan datang. Tujuan penelitian ini adalah untuk menjelaskan peran kepuasan pelanggan memediasi persepsi harga terhadap loyalitas pelanggan. Penelitian ini dilakukan pada pelanggan produk McDonald's di Kota Denpasar. Teknik analisis yang digunakan adalah analisis jalur. Jumlah sampel yang digunakan dalam penelitian ini adalah sebanyak 120 responden, dengan metode purposive sampling. Pengumpulan data dilakukan melalui kuesioner, wawancara, dan observasi. Berdasarkan hasil penelitian yang dilakukan, ditemukan kepuasan pelanggan mampu memediasi pengaruh persepsi harga terhadap loyalitas pelanggan. Ini dibuktikan dengan persepsi harga berpengaruh positif dan signifikan terhadap loyalitas pelanggan; persepsi harga berpengaruh positif dan signifikan terhadap kepuasan pelanggan; kepuasan pelanggan berpengaruh positif dan signifikan terhadap loyalitas pelanggan; serta kepuasan pelanggan berperan sebagai variabel mediasi antara persepsi harga dan loyalitas pelanggan.
\end{abstract}

Kata Kunci : persepsi harga, kepuasan pelanggan, loyalitas pelanggan

\begin{abstract}
Customer loyalty is a form of customer loyalty to loyal or continue to use products or services from the same company in the future. The purpose of this study is to explain the role of customer satisfaction mediate the perception of price to customer loyalty. This research was conducted on customer of McDonald's product in Denpasar City. The analysis technique used is path analysis. The number of samples used in this study were as many as 120 respondents, with purposive sampling method. The data were collected through questionnaires, interviews, and observations. Based on the results of research conducted, found customer satisfaction is able to mediate the influence of price perceptions on customer loyalty. This is evidenced by the perception of prices have a positive and significant impact on customer loyalty; price perceptions have a positive and significant impact on customer satisfaction; customer satisfaction has a positive and significant impact on customer loyalty; and customer satisfaction acts as a mediating variable between price perceptions and customer loyalty.
\end{abstract}

Keywords: price perception, customer satisfaction, customer loyalty 


\section{PENDAHULUAN}

Era global yang semakin maju dan pola hidup serba praktis menuntut segala sesuatunya dilakukan dengan serba cepat. Perkembangan situasi ini menggiring konsumen dan pelanggan untuk senantiasa mencari produk yang dapat dikonsumsi dengan waktu yang cepat namun tetap dapat memberikan manfaat yang sama. Konsumen bahkan mulai terbiasa memenuhi kebutuhan primernya menjadi serba praktis. Masyarakat dewasa cenderung memilih makanan dari restoran cepat saji (fast food). Fast food semakin diminati karena dianggap dapat memenuhi kebutuhan konsumsi bagi masyarakat yang sibuk dengan pekerjaannya dan memiliki keterbatasan waktu (Mufidah, 2012).

Fast food merupakan salah satu pilihan kuliner yang digemari masyarakat, khususnya mereka yang tinggal di perkotaan. Fast food disajikan secara praktis dengan waktu persiapannya yang singkat, sehingga dapat menghemat waktu untuk makan ketika seseorang memiliki aktivitas yang padat. Harga yang ditawarkan oleh produsen fast food cukup terjangkau jika dibandingkan dengan harus mengolah bahan makanan yang dibeli sendiri. Menurut Mufidah (2012), kesibukan orang tua untuk berkarir menyebabkan mereka tidak memiliki waktu untuk menyiapkan makanan di rumah, sehingga lebih memilih untuk membeli makanan di luar rumah yang tentunya dapat diperoleh dengan waktu yang singkat. Mayoritas masyarakat Indonesia lebih menyukai berkunjung ke outlet cepat saji dibandingkan jenis restoran lainnya ketika ingin makan di luar rumah. Surve terbaru dari Master Card bertajuk Consumer Purchasing Priorities menyatakan bahwa sebanyak 80 persen masyarakat di Indonesia lebih memilih untuk 
I Putu Eka Astra Prasad, Peran Kepuasan Pelanggan Memediasi Pengaruh Persepsi...

bersantap di outlet cepat saji, diikuti oleh pusat jajanan atau food court sebanyak 61 persen, dan restoran atau kafe kelas menengah sebanyak 22 persen, dan hanya sekitar 1 persen yang memilih mengunjungi restoran untuk jamuan makan resmi (fine dining).

Anang Sukandar selaku CEO Indonesia Franchise Association (IFA), meningkatnya pelaku bisnis waralaba fast food pada Tahun 2017 menyebabkan persaingan di industri ini menjadi semakin kompetitif. Persaingan yang kompetitif ini dialami oleh Kentucky Fried Chicken (KFC), McDonald's , Hoka Hoka Bento dan Pizza Hut. Menurut Health Education Authority (2002), konsumen fast food rata-rata berusia 15 sampai 34 tahun.

Surve awal yang dilakukan terhadap 20 orang responden yang telah melakukan pembelian lebih dari sekali di McDonald's Denpasar, menunjukkan hasil bahwa 60 persen responden tidak puas dengan harga produk yang ditawarkan oleh McDonald's Denpasar. Responden menilai bahwa harga produk McDonald's tidak sesuai dengan harapan pelanggan, karena harga yang tinggi seharusnya dapat diimbangi dengan kualitas produk atau citra rasa yang sesuai selera pelanggan, sehingga hal ini secara otomatis berdampak pada berkurangnya loyalitas pelanggan.

Kondisi ini mengakibatkan pelanggan dihadapkan pada berbagai pilihan produk dengan harga dan kualitas yang bervariasi, kemudian pelanggan senantiasa akan mencari nilai tertinggi dari produk-produk tersebut dan tentunya dapat membuat pelanggan merasa puas dan loyal (Masitha dan Heru, 2014). Loyalitas pelanggan sangat penting bagi suatu perusahaan atau waralaba, sebab 
pelanggan yang setia adalah pelanggan yang sangat puas dengan produk dan pelayanan tertentu, sehingga mempunyai niat untuk memperkenalkannya kepada siapapun (Griffin, 2005:31). Caruana (2002) menyatakan bahwa loyalitas pelanggan merupakan bagian terpenting dari terciptanya pembelian ulang yang dilakukan pelanggan terhadap produk atau jasa. Lovelock dan Wright (2007:133), menyatakan bahwa loyalitas pelanggan adalah kesedian pelanggan untuk terus berlangganan pada sebuah perusahaan dalam jangka panjang dengan membeli dan menggunakan barang dan jasanya secara berulang-ulang dan secara suka rela merekomendasikan produk perusahaan tersebut kepada teman-temannya.

Tjahjaningsih (2013) menyatakan bahwa untuk memperoleh loyalitas pelanggan, perusahaan harus memperhatikan kepuasan pelanggan. Menurut Zeithaml dan Bitner (2008:110) kepuasan pelanggan merupakan respon pelanggan terhadap evaluasi yang dirasakan antara harapan dan kinerja aktual jasa. Bowen dan Shiang (2001) menyatakan kepuasan pelanggan sangat erat hubungannya dengan loyalitas pelanggan, dimana pelanggan yang terpuaskan akan menjadi pelanggan yang loyal. Kepuasan (satisfaction) adalah perasaan senang atau kecewa seseorang yang timbul karena membandingkan kinerja produk yang di persepsikan konsumen terhadap ekspektasi konsumen (Kotler dan Keller 2017:177).

Harga merupakan faktor penting dalam menimbulkan kepuasan pelanggan (Virvilaite et al., 2009). Menurut Fata dkk. (2015) harga memiliki pengaruh yang positif dalam memberikan kepuasan pelanggan. Persepsi terhadap harga akan mencerminkan cara pandang konsumen dalam melihat produk tersebut. Ketika 
I Putu Eka Astra Prasad, Peran Kepuasan Pelanggan Memediasi Pengaruh Persepsi...

harga yang tinggi ditawarkan bersamaan dengan pengharapan yang tinggi, maka pelanggan akan merasakan suatu kepuasan terhadap produk tersebut. Namun, ketika harga yang ditawarkan tinggi ditawarkan dengan pengharapan yang rendah maka secara otomatis konsumen cenderung tidak terpuaskan. Saladin (2007:95) menyatakan bahwa harga adalah penentu nilai dalam benak pelanggan dengan mengeluarkan nilai tukar sebagai suatu cara untuk mendapatkan suatu produk.

Darmawan dan Ekawati (2017) mengungkapkan bahwa harga berpengaruh positif dan signifikan terhadap loyalitas pelanggan. Hasil yang bertentangan ditemukan oleh Naehyun et al. (2016) mengungkapkan bahwa harga berpengaruh tidak signifikan terhadap loyalitas pelanggan. Consuegra et al. (2007) mengungkapkan bahwa harga berpengaruh positif dan signifikan terhadap kepuasan pelanggan. Hasil yang bertentangan ditemukan oleh Sulistiyanto W.S dan Euis (2015) bahwa harga tidak berpengaruh terhadap kepuasan pelanggan.

Berdasarkan research gap tersebut, maka penelitian ini dimaksudkan untuk pengembangan studi dari berbagai penelitian yang telah dilakukan sebelumnya. Perbedaan penelitian ini dengan penelitian sebelumnya adalah objek penelitiannya yaitu pelanggan produk McDonald's di Kota Denpasar. McDonald's dipilih karena merupakan restoran cepat saji yang meraup penjualan terbesar di dunia menurut surve yang dilakukan oleh QSR (Quick Service Restaurant) Magazine pada tahun 2012. Hal tersebut menunjukkan adanya kesenjangan antara data dan fenomena yang terjadi di lapangan. Meskipun, McDonald's meraup penjualan terbesar di dunia, namun hasil surve di lapangan menunjukkan bahwa masih banyak responden yang tidak puas terhadap produk McDonald's di Kota 
Denpasar, karena tidak sesuai dengan harapan pelanggan. Berikut daftar 10 restoran cepat saji yang meraup penjualan terbesar di dunia ditampilkan pada Tabel 1.

Tabel 1.

Daftar Restoran Cepat Saji dengan Penjualan Terbesar di Dunia

\begin{tabular}{clrr}
\hline No. & \multicolumn{1}{c}{ Restoran Cepat Saji } & \multicolumn{1}{c}{$\begin{array}{c}\text { Penjualan } \\
\text { (Non-Amerika Serikat) }\end{array}$} & $\begin{array}{r}\text { Jumlah Unit Toko } \\
\text { (di luar AS) }\end{array}$ \\
\hline 1 & McDonald's & 44,98 miliar dollar AS & 18.710 unit \\
2 & KFC & 14,7 miliar dollar AS & 11.798 unit \\
3 & Burger King Corp & 6,2 miliar dollar AS & 4.998 unit \\
4 & Pizza Hut & 4,8 miliar dollar AS & 5.890 unit \\
5 & Subway & 4,6 miliar dollar AS & 10.109 unit \\
6 & Domino Pizza & 2,9 miliar dollar AS & 4.422 unit \\
7 & Starbucks Cofee Company & 2,29 miliar dollar AS & 5.727 unit \\
8 & Wendys & 982,7 juta dollar AS & 693 unit \\
9 & Dunkin Donuts & 433,1 juta dollar AS & 3.005 unit \\
10 & Dairy Queen & 353,9 juta dollar AS & 802 unit \\
\hline \multicolumn{2}{l}{ Sumber $:$ Kompas.Com, 2013 }
\end{tabular}

Tabel 1 menerangkan bahwa McDonald's sebagai restoran cepat saji memiliki penjualan yang lebih tinggi dibandingkan dengan fast food lainnya yaitu dengan total penjualan sebear 44,99 miliar dollar AS dan dengan jumlah unit toko sebanyak 18.710 unit.

Persebaran restoran cepat saji khususnya di Denpasar sangat tinggi dilihat dari keberadaannya yang menjamur di pusat-pusat kota. Denpasar menjadi sasaran utama didirikannya restoran cepat saji seperti McDonald's, KFC, Burger King dan Pizza Hut karena Denpasar adalah kota berpenduduk padat. Pada tahun 2016 Dinas Penduduk dan Pencatatan Sipil mencatat banyaknya penduduk Kota Denpasar mencapai 164,199 jiwa. Selain itu, Denpasar merupakan kota sasaran bagi pendatang luar daerah karena dianggap sebagai pusat lapangan kerja, pelayanan kesehatan, dan juga pusat pendidikan terbaik di Bali. Peningkatan jumlah penduduk juga dibarengi dengan meningkatnya kebutuhan yang harus 
I Putu Eka Astra Prasad, Peran Kepuasan Pelanggan Memediasi Pengaruh Persepsi...

dipenuhi. Sebagian masyarakat Kota Denpasar yang memiliki kesibukan tinggi cenderung mengkonsumsi makanan cepat saji untuk efisiensi waktu dengan harga yang cukup terjangkau. Sehingga tidak heran jika telah didirikan enam outlet McDonald's di Kota Denpasar. Peluang tersebut dimanfaatkan oleh McDonald's untuk memanjakan pelanggannya dengan menawarkan menu yang variatif, mulai dari burger, salad, spaghetti, fried chicken, dan aneka minuman dengan berbagai alternatif harga. Tabel 2 menampilkan variasi harga produk McDonald's tahun 2016-2017 di Kota Denpasar dengan kisaran harga Rp.2.500 - Rp.41.000 pada tahun 2016 dan Rp.4.545 - Rp.42.727 pada tahun 2017.

Tabel 2.

Daftar Harga McDonald's di Kota Denpasar Tahun 2016-2017

\begin{tabular}{ccr}
\hline No. & Tahun & \multicolumn{1}{c}{ Harga (Rupiah) } \\
\hline 1. & 2016 & $2.500-41.000$ \\
2. & 2017 & $4.545-42.727$ \\
\hline
\end{tabular}

Sumber: hargamenu.net dan hargamenuterbaru.com, 2017

Berdasarkan latar belakang, peneliti tertarik untuk melakukan replikasi penelitian yang di lakukan oleh Darmawan dan Ekawati (2017). Tujuan yang ingin dicapai dalam penelitian ini adalah untuk menjelaskan pengaruh persepsi harga terhadap kepuasan pelanggan di McDonald's di Kota Denpasar, untuk menjelaskan pengaruh persepsi harga dan kepuasan pelanggan terhadap loyalitas pelanggan di McDonald's di Kota Denpasar, dan untuk menjelaskan peran kepuasan pelanggan dalam memediasi persepsi harga terhadap loyalitas pelanggan McDonald's di Kota Denpasar. 


\section{Pengaruh persepsi harga terhadap kepuasan pelanggan}

Menurut Saladin (2007:95), harga merupakan sejumlah uang yang digunakan sebagai alat tukar untuk memperoleh produk atau jasa yang bisa dikatakan sebagai penentu nilai di dalam benak konsumen. Persepsi harga yang dimilki setiap individu berbeda-beda karena persepsi harga menunjukan perbedaan dimana harga yang dirasakan konsumen setelah membeli atau mengkonsumsi produk. Kepuasan akan bisa dirasakan konsumen jika harga yang dipersepsikan konsumen sesuai dengan harapan konsumen.

Harga merupakan faktor terpenting dalam memuaskan konsumen (Virvilaite et al., 2009). Harga adalah instrumen yang sangat penting dalam perilaku yang signifikan dengan konsumen, baik itu bertambah maupun berkurangnya kepuasaan dan kepercayaan konsumen. Penelitian yang dilakukan oleh Fata dkk. (2015), menyatakan bahwa variabel harga berpengaruh signifikan terhadap kepuasan konsumen. Suwarni dan Septina (2011), Razak (2016), Wijaya dan Nurcaya (2017) menyatakan bahwa dalam penelitiannya harga memiliki pengaruh yang positif dan signifikan terhadap kepuasan pelanggan. Namun hasil penelitian yang berbeda yang ditemukan Sulistiyanto W.S dan Euis (2015) yang menunjukkan bahwa persepsi harga tidak berpengaruh terhadap peningkatan kepuasan pelanggan, sehingga semakin baik persepsi harga maka tidak akan meningkatkan kepuasan pelanggan. Berdasarkan hasil penelitian yang telah dijabarkan di atas, maka dalam penelitian ini hipotesis yang dapat ditarik adalah sebagai berikut:

$\mathrm{H}_{1}$ : Persepsi harga berpengaruh signifikan terhadap kepuasan pelanggan. 
I Putu Eka Astra Prasad, Peran Kepuasan Pelanggan Memediasi Pengaruh Persepsi...

\section{Pengaruh persepsi harga terhadap loyalitas pelanggan}

Menurut Harald (dalam Surya dan Setya Ningrum, 2009) yang menyatakan konsep harga berhubungan dengan profitabilitas produk, tingkat harga kompetitif dan syarat-syarat pembelian. Konsumen akan loyal jika mentetapkan harga produk yang sebanding dengan nilai manfaat yang diberikan kepada konsumen (Aliasadi et al., 2014). Keadilan harga mempengaruhi loyalitas dimana kenaikan harga bisa mempengaruhi loyalitas konsumen. Tomida dan Budhi (2016) dan Darmawan dan Ekawati (2017) menyatakan bahwa harga berpengaruh positif terhadap loyalitas pelanggan. Pengaruh positif ini memberikan makna bahwa konsumen akan loyal jika perusahaan menetapkan harga produk yang sebanding dengan nilai manfaat yang diberikan kepada konsumen. Namun penelitian yang dilakukan oleh Suwarni dan Septina (2011), menemukan bahwa tidak terdapat pengaruh yang signifikan antara harga terhadap loyalitas pelanggan. Berdasarkan hasil penelitian yang telah dijabarkan di atas maka dalam penelitian ini hipotesis yang dapat ditarik sebagai berikut:

$\mathrm{H}_{2}$ : Persepsi harga berpengaruh signifikan terhadap loyalitas pelanggan.

\section{Pengaruh kepuasan pelanggan terhadap loyalitas pelanggan}

Menurut Dimyati (2015) kepuasan pelanggan berpengaruh positif dan signifikan terhadap loyalitas pelanggan. Jahanshahi et al. (2011); Ashgarian et al. (2012); Colognesi dan Alit (2015); Raharjo (2013) dan Kaura Vinita et al. (2015) menyatakan kepuasan pelanggan berpengaruh positif terhadap loyalitas pelanggan, artinya jika perusahaan dapat meningkatkan kepuasan pelanggannya, 
maka pelanggan yang dimiliki perusahaan akan semakin loyal dan jika kepuasan pelanggan mengalami perubahan maka loyalitas pelanggan akan langsung ikut mengalami perubahan. Namun penelitian yang berbeda ditemukan oleh Sulistiyanto W.S dan Euis (2015) menyatakan kepuasan pelanggan tidak berpengaruh terhadap loyalitas pelanggan, sehingga kepuasan pelanggan yang semakin baik maka tidak akan meningkatkan loyalitas pelanggan. Berdasarkan hasil penelitian yang telah dijabarkan di atas maka dalam penelitian ini hipotesis yang dapat ditarik sebagai berikut:

$\mathrm{H}_{3}$ : Kepuasan pelanggan berpengaruh signifikan terhadap loyalitas pelanggan.

\section{Peran kepuasan pelanggan memediasi pengaruh persepsi harga terhadap loyalitas pelanggan}

Kurniasih (2012) dan Putra dan Edy (2012) menyatakan bahwa harga berpengaruh terhadap loyalitas. Harga berpengaruh terhadap kepuasan pelanggan dan kepuasan pelanggan berperan sebagai variabel intervening antara harga dan loyalitas pelanggan. Penelitan yang dilakukan oleh Sulistiyanto W.S dan Euis (2015) mengungkapkan kepuasan pelanggan tidak berpengaruh terhadap persepsi harga dan loyalitas pelanggan. Berdasarkan hasil penelitian yang telah dijabarkan di atas maka dalam penelitian ini hipotesis yang dapat ditarik sebagai berikut:

$\mathrm{H}_{4}$ : Kepuasan pelanggan memediasi persepsi harga terhadap loyalitas pelanggan.

Berdasarkan penelusuran kajian pustaka dan hasil-hasil penelitian terdahulu. Maka model penelitian dalam penelitian ini adalah sebagi berikut. 


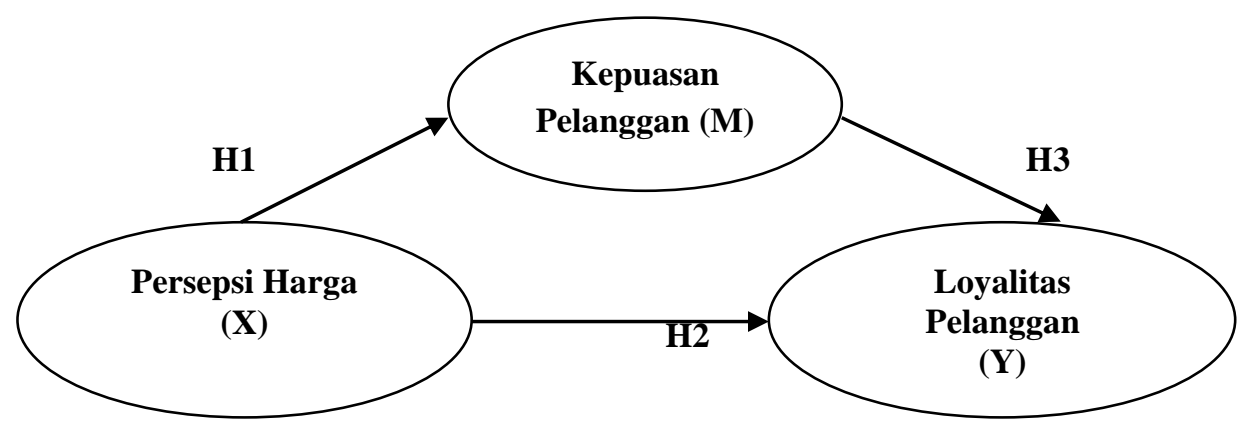

\section{Gambar 1. Kerangka Konseptual}

Sumber : Darmawan dan Ekawati (2017)

\section{METODE PENELITIAN}

Penelitian ini menggunakan pendekatan kuantitatif yang berbentuk asosiatif (hubungan), yaitu penelitian yang bertujuan untuk mengetahui hubungan dari variabel. Untuk mendapatkan hasil penelitian yang baik, maka dibutuhkan desain penelitian untuk menunjang dan memberikan hasil penelitian yang sistematik. Penelitian ini dilakukan di kota Denpasar, karena Denpasar sebagai ibu kota berpenduduk padat yang dilihat dari Dinas Penduduk dan Pencatatan Sipil tahun terakhir yaitu 2016 sebanyak 164.199 jiwa yang mana kebutuhannya setiap tahunnya semakin meningkat. Denpasar merupakan kota sasaran bagi pendatang luar daerah sebagai pusat lapangan kerja, pelayanan kesehatan, ataupun pusat pendidikan. Lokasi McDonald's terletak di Kota Denpasar.

Subjek penelitian ini adalah pelanggan McDonald's di Kota Denpasar dengan kata lain pelanggan yang sudah pernah berbelanja lebih dari sekali atau sedang berbelanja di McDonald's yang ada di Kota Denpasar dalam kurun waktu 3 sampai 6 bulan. Objek dalam penelitian yaitu loyalitas pelanggan dalam berbelanja pada McDonald's yang ada di Kota Denpasar. 
Variabel dan indikator yang digunakan dalam penelitian ini terangkum dalam Tabel 3 sebagai berikut :

Tabel 1.

Klasifikasi variabel dan Indikator Penelitian

\begin{tabular}{|c|c|c|c|}
\hline $\begin{array}{c}\text { Klasifikasi } \\
\text { Variabel }\end{array}$ & Variabel & Indikator & Sumber \\
\hline Independen & $\begin{array}{l}\text { Persepsi } \\
\text { Harga } \\
(\text { X ) }\end{array}$ & $\begin{array}{l}\text { 1) Harga yang terjangkau pelanggan }\left(X_{1.1}\right) \\
\text { 2) Harga sesuai dengan kualitas }\left(X_{1.2}\right) \\
\text { 3) Harga yang ditawarkan harga wajar }\left(X_{1.3}\right) \\
\text { 4) Harga sesuai dengan informasi }\left(X_{1.4}\right)\end{array}$ & $\begin{array}{l}\text { Erlangga dan } \mathrm{H} \text {, } \\
\text { Sutopo (2012; } \\
\text { Consuegra et al. } \\
(2007) ; \\
\text { Nofita dan } \\
\text { Kamal (2013) }\end{array}$ \\
\hline Mediasi & $\begin{array}{l}\text { Kepuasan } \\
\text { Pelanggan } \\
\text { (M) }\end{array}$ & $\begin{array}{l}\text { 1) Kepuasan keseluruhan }\left(\mathrm{M}_{1.1}\right) \\
\text { 2) Tingkat kinerja produk dengan } \\
\text { pengharapannya }\left(\mathrm{M}_{1.2}\right) \\
\text { 3) Kinerja produk dibandingkan dengan } \\
\text { produk ideal }\left(\mathrm{M}_{1.3}\right)\end{array}$ & $\begin{array}{l}\text { Ruth Amryyanti } \\
\text { dkk., (2013) }\end{array}$ \\
\hline Dependen & $\begin{array}{l}\text { Loyalitas } \\
\text { pelanggan } \\
\text { (Y) }\end{array}$ & $\begin{array}{l}\text { 1) Pembelian berulang }\left(Y_{1.1}\right) \\
\text { 2) Membeli antar lini produk }\left(Y_{1.2}\right) \\
\text { 3) Mereferensikan kepada orang lain }\left(Y_{1.3}\right) \\
\text { 4) Kekebalan terhadap pesaing }\left(Y_{1.4}\right) \\
\text { 5) Komitmen pada produk }\left(Y_{1.5}\right)\end{array}$ & $\begin{array}{l}\text { Griffin } \\
(2005: 31) ; \\
\text { Putra dan } \\
\text { Ekawati (2017) }\end{array}$ \\
\hline
\end{tabular}

Populasi dalam penelitian ini adalah pelanggan yang pernah berbelanja di McDonald's. Sedangkan sampel adalah bagian dari populasi yang di harapkan dapat mewakili keseluruhan populasi tersebut (Sugiyono, 2012:118). Metode penentuan sampel dalam penelitian ini menggunakan metode non probability sampling, dimana tidak semua anggota populasi memiliki kesempatan atau peluang yang sama untuk menjadi sampel. Menggunakan teknik pengambilan sampel yaitu purposive sampling adalah teknik pengambilan sample berdasarkan kriteria tertentu. Adapun kriteria dari penentuan sampel penelitian ini adalah responden minimal pendidikan SMA karena jika sudah SMA dinilai sudah dewasa dan bisa menjawab kuesioner tersebut. Kriteria kedua yaitu responden pernah berbelanja di McDonald's yang ada di Kota Denpasar lebih dari 1 kali dalam 
I Putu Eka Astra Prasad, Peran Kepuasan Pelanggan Memediasi Pengaruh Persepsi...

periode 3 sampai 6 bulan atau sedang berbelanja di McDonald's yang ada di Kota Denpasar lebih dari 1 kali dalam 3 sampai 6 bulan terakir.

Beberapa aturan dalam penentuan ukuran sampel, diantaranya adalah ukuran sampel lebih dari 30 dan kurang dari 500 adalah tepat untuk kebanyakan penelitian. Ukuran sampel yang dianggap representatif dapat ditentukan paling sedikit 5 sampai 10 kali jumlah indikator yang diteliti. Jumlah indikator dalam penelitian ini adalah sebanyak 12 indikator, maka jumlah sampel yang ideal dalam penelitian adalah berkisar antara 60 hingga 120 responden. Jadi ukuran sampel yang digunakan dalam penelitian ini sebanyak 12 indikator x $10=120$ responden.

Penelitian ini memakai teknik analisis jalur atau biasa disebut path analysis, untuk menganalisis pola hubungan antar variabel dengan tujuan untuk mengetahui pengaruh langsung ataupun tidak langsung suatu variabel bebas (persepsi harga) terhadap variabel terikat (loyalitas pelanggan), dengan persamaan struktur sebagai berikut :

Substruktur $1: M=\beta 1 X+\varepsilon 1$

Substruktur $2: \mathrm{Y}=\beta 2 \mathrm{X}+\beta 3 \mathrm{M}+\varepsilon 2$

Keterangan :

$$
\begin{array}{ll}
\mathrm{Y} & =\text { Loyalitas Pelanggan } \\
\mathrm{X} & =\text { Persepsi Harga } \\
\mathrm{M} & =\text { Kepuasan Pelanggan } \\
\beta_{2} & =\text { Koefisien regresi variabel } \\
e_{1} e_{2} & =\text { Error }
\end{array}
$$

Pengujian Hipotesis Mediasi dalam penelitian ini menggunakan uji Sobel atau biasa disebut dengan Sobel test. Uji Sobel atau sobel test dipakai untuk menguji seberapa kekuatan pengaruh tidak langsung antara variabel persepsi 
harga (X) ke variabel loyalitas pelanggan (Y) melalui variabel kepuasan pelanggan (M), dihitung dengan cara mengalikan antara koefisien jalur X terhadap M (a), dengan koefisien jalur M terhadap Y (b) atau ab. Standard error dari koefisien a dan $\mathrm{b}$ nantinya ditulis dengan huruf atau simbol $\mathrm{S}_{\mathrm{a}}$ dan $\mathrm{S}_{\mathrm{b}}$, dan besarnya standard error tidak langsung (indirect effect) $\mathrm{S}_{\mathrm{a}}$. Uji sobel dihitung memakai rumus dibawah ini:

$$
\begin{aligned}
& Z=\frac{a b}{\sqrt{b^{2} s_{a}^{2}+a^{2} s_{b}^{2}+s_{a}^{2} s_{b}^{2}}} . \\
& \operatorname{Sig}=(1-\operatorname{NORMDIST}(Z))+2)
\end{aligned}
$$

Keterangan:

$\mathrm{a}=$ koefisien regresi dari variabel bebas $(\mathrm{X})$ terhadap variabel mediasi (M)

$\mathrm{s}_{\mathrm{a}}=$ standard eror dari $\mathrm{a}$

$\mathrm{b}=$ koefisien regresi dari variabel mediasi terhadap variabel dependen (Y)

$\mathrm{sb}_{\mathrm{b}}=$ standard eror dari $\mathrm{b}$

\section{HASIL DAN PEMBAHASAN}

Data penelitian diperoleh dari hasil kuesioner yang telah disebarkan kepada responden penelitian sejumlah 120 orang pelanggan McDonald's di Kota Denpasar. Karakteristik responden meliputi jenis kelamin, usia, tingkat pendidikan terakhir dan pekerjaan responden yang dirangkum pada Tabel 4 .

Karakteristik responden ditinjau dari jenis kelamin menunjukkan bahwa mayoritas responden berjenis kelamin pria dengan jumlah sebanyak 85 responden dan sisanya 35 responden berjenis kelamin wanita. Perbedaan angka tidak terlalu berselisih jauh, ini menunjukan bahwa masyarakat khususnya di Kota Denpasar 
I Putu Eka Astra Prasad, Peran Kepuasan Pelanggan Memediasi Pengaruh Persepsi...

memiliki tingkat loyalitas pelanggan produk McDonald's yang baik. Hasil tersebut mengindikasikan produk yang ditawarkan McDonald's tidak menyasar hanya satu gender saja melainkan dapat diterima dan dirasakan manfaatnya oleh kaum pria dan wanita khususnya di Kota Denpasar.

Tabel 4.

Karakteristik Responden

\begin{tabular}{llcc}
\hline No & Kriteria & Klasifikasi & Jumlah (Responden) \\
\hline 1. & Jenis Kelamin & Pria & 85 \\
& & Wanita & 35 \\
& & $19-21$ & 68 \\
2. & Usia (Thn) & $22-26$ & 39 \\
& & $27-31$ & 2 \\
& $32-36$ & 0 \\
& & $37-42$ & 1 \\
& & Diatas 42 & 10 \\
& & SMA / Sederajat & 91 \\
3. & Diploma & 3 \\
& Pendidikan Terakhir & S1 & 23 \\
& & S2 & 3 \\
& & S3 & 0 \\
& & Pelajar / mahasiswa & 93 \\
& & Karyawan Swasta & 12 \\
4. & Pekerjaan & Pegawai Negeri Sipil) & 4 \\
& & Pengusaha & 9 \\
& & Lain-lain & 2 \\
& & &
\end{tabular}

Sumber: data diolah, 2018

Kriteria usia yang mendominasi dalam penelitian ini adalah rentang usia 19 sampai 21 tahun dengan jumlah sebanyak 68 responden. Hal tersebut menandakan bahwa produk-produk yang ditawarkan McDonald's dengan kualitas dan harga yang ditawarkan dapat menarik perhatian konsumen pada rentang umur 19-21 tahun cenderung untuk melihat varian produk yang ditawarkan oleh McDonald's sebagai daya tarik tambahan sehingga responden pada rentang usia ini memiliki minat yang tinggi untuk mengunjungi McDonald's. 
Tabel 4 menunjukkan bahwa mayoritas responden memiliki pendidikan terakhir SMA/Sederajat yaitu dengan jumlah sebanyak 91 responden. Data tersebut menunjukan bahwa konsumen McDonald's khususnya di Kota Denpasar dominan adalah responden dengan tingkat pendidikan SMA/Sederajat. Hal ini berkaitan dengan tingkat pemahaman akan persepsi harga dan kepuasan pelanggan yang nantinya akan dapat menimbulkan loyalitas pelanggan yang mengakibatkan respon positif konsumen untuk kembali membeli produk McDonald's sehingga akan terbentuk loyalitas masyarakat khususnya di Kota Denpasar terhadap produk yang ditawarkan McDonald's.

Data menunjukkan bahwa responden yang memiliki status pekerjaan sebagai pelajar atau mahasiswa/i memiliki angka tertinggi yaitu sebesar 93 responden. Hal ini berarti harga yang ditawarkan produk McDonald's sesuai dengan daya beli pelajar / mahasiswa/i dan disertai dengan sesuai pengharapan pelanggan pada status pekerjaan tersebut. Pada masa sekolah ataupun kuliah, pelajar atau mahasiswa/i sering mengunjungi McDonald's sebagai tempat mengejarkan tugas kuliah ataupun tugas sekolah, karena McDonald's menawarkan fasilitas free wi-fi sehingga dapat membantu menyelesaikan tugas tersebut.

Hasil kuesioner yang telah disebarkan kepada responden penelitian sejumlah 120 orang pelanggan McDonald's di Kota Denpasar kemudian di uji kelayakannya sebagai instrumen dalam pengumpulan data dengan analisis uji validitas dan reliabilitas. Hasil uji validitas penelitian ini menunjukan bahwa seluruh indikator mempunyai pearson correlation melebihi angka 0,30. Maka, 
I Putu Eka Astra Prasad, Peran Kepuasan Pelanggan Memediasi Pengaruh Persepsi...

dapat disimpulkan bahwa indikator-indikator pada variabel persepsi harga, kepuasan pelanggan dan loyalitas pelanggan telah memenuhi syarat validitas data sehingga dapat digunakan sebagai instrumen penelitian. Sedangkan hasil uji reliabilitas penelitian ini menunjukkan bahwa seluruh instrumen penelitian mempunyai koefisen cronbach's alpha melebihi 0,60 (reliable), yang dimana variabel persepsi harga memiliki cronbach alpha 0,765 , kepuasan pelanggan 0,657 , dan loyalitas pelanggan 0,882 .

Setelah hasil kuesioner dinyatakan layak untuk digunakan sebagai instrumen dalam pengumpulan data, maka selanjutnya di analisis dengan hasil uji statistik deskriptif, yang secara rinci dijabarkan dalam Tabel 5 hinggal Tabel 7.

Tabel 5.

Deskripsi Persepsi Responden Terhadap Persepsi Harga

\begin{tabular}{|c|c|c|c|c|c|c|c|c|c|}
\hline \multirow[t]{2}{*}{ No } & \multirow[t]{2}{*}{ Indikator } & \multicolumn{5}{|c|}{ Proporsi Persepsi Responden (\%) } & \multirow{2}{*}{$\begin{array}{l}\text { Jumlah } \\
\text { skor }\end{array}$} & \multirow{2}{*}{$\begin{array}{l}\text { Rata- } \\
\text { rata }\end{array}$} & \multirow[t]{2}{*}{ Ket } \\
\hline & & 1 & 2 & 3 & 4 & 5 & & & \\
\hline 1 & $\begin{array}{l}\text { Harga yang terjangkau } \\
\text { bagi pelanggan }\end{array}$ & 0 & 3 & 28 & 60 & 29 & 475 & 3,96 & Sesuai \\
\hline 2 & $\begin{array}{l}\text { Harga sesuai dengan } \\
\text { kualitas }\end{array}$ & 0 & 3 & 22 & 82 & 13 & 465 & 3,88 & Sesuai \\
\hline 3 & $\begin{array}{l}\text { Harga yang di } \\
\text { tawarkan harga yang } \\
\text { wajar }\end{array}$ & 0 & 3 & 39 & 58 & 20 & 455 & 3,79 & Sesuai \\
\hline 4 & $\begin{array}{l}\text { Harga akan sesuai } \\
\text { dengan informasi }\end{array}$ & 1 & 4 & 27 & 62 & 26 & 468 & 3,90 & Sesuai \\
\hline \multicolumn{8}{|c|}{ Rata-rata keseluruhan variabel persepsi harga } & 3,88 & Sesuai \\
\hline
\end{tabular}

Hasil perhitungan Tabel 5 menunjukan bahwa secara keseluruhan pada variabel persepsi harga dengan rata-rata total sebesar 3,88 persen dan masuk dalam kriteria sesuai. Hal ini menunjukan bahwa responden mempersepsikan harga McDonald's sudah sesuai dengan produk yang ditawarkan McDonald's. Variabel persepsi harga yang diukur dengan empat indikator, menunjukan nilai rata-rata tertinggi terdapat pada indikator harga yang terjangkau bagi pelanggan 
dengan nilai sebesar 3,96 persen. Pada pernyataan tersebut sebanyak 29 persen menyatakan sangat setuju, 60 persen menyatakan setuju, 28 persen menyatakan cukup setuju, 3 persen menyatakan tidak setuju dan 0 persen menyatakan sangat tidak setuju. Hal ini menunjukan harga produk McDonald's dinilai responden terjangkau bagi pelanggannya.

Skor terendah dengan nilai rata-rata 3,79 pada indikator harga yang ditawarkan harga yang wajar dalam pernyataan tersebut dalam pernyataan tersebut sebanyak 20 persen menyatakan sangat setuju, 58 persen menyatakan setuju, 39 persen menyatakan cukup setuju, 3 persen menyatakan tidak setuju dan 0 persen menyatakan sangat tidak setuju. Hal ini menunjukan tidak semua responden mempersepsikan harga yang ditawarkan McDonald's adalah harga yang wajar.

Tabel 6.

Deskripsi Persepsi Responden Kepuasan Pelanggan

\begin{tabular}{|c|c|c|c|c|c|c|c|c|c|}
\hline \multirow[t]{2}{*}{ No. } & \multirow[t]{2}{*}{ Indikator } & \multicolumn{5}{|c|}{ Proporsi Persepsi Responden (\%) } & \multirow{2}{*}{$\begin{array}{c}\text { Jumlah } \\
\text { skor }\end{array}$} & \multirow{2}{*}{$\begin{array}{l}\text { Rata } \\
\text {-rata }\end{array}$} & \multirow[t]{2}{*}{ Ket } \\
\hline & & 1 & 2 & 3 & 4 & 5 & & & \\
\hline 1 & Kepuasan keseluruhan & 0 & 1 & 25 & 65 & 29 & 482 & 4,02 & Puas \\
\hline 2 & $\begin{array}{l}\text { Tingkat kinerja produk } \\
\text { dengan } \\
\text { pengaharapannya }\end{array}$ & 0 & 3 & 28 & 68 & 21 & 467 & 3,89 & Puas \\
\hline 3 & $\begin{array}{l}\text { Kinerja produk } \\
\text { dibandingkan dengan } \\
\text { produk ideal }\end{array}$ & 0 & 8 & 28 & 60 & 24 & 460 & 3,83 & Puas \\
\hline Rata- & ata keseluruhan variabel & pus & & & & & 1409 & 3,91 & Puas \\
\hline
\end{tabular}

Hasil perhitungan berdasarkan Tabel 6 menunjukan bahwa secara keseluruhan pada variabel kepuasan pelanggan dengan rata-rata total sebesar 3,91 persen dan masuk dalam kriteria baik. Hal ini menunjukan bahwa responden puas terhadap produk McDonald's. Variabel kepuasan pelanggan yang diukur menggunakan tiga indikator, menunjukan nilai rata-rata tertinggi terdapat pada indikator kepuasan keseluruhan dengan nilai sebesar 4,02 persen. Pada pernyataan 
I Putu Eka Astra Prasad, Peran Kepuasan Pelanggan Memediasi Pengaruh Persepsi...

tersebut sebanyak 29 persen menyatakan sangat setuju, 65 persen menyatakan setuju, 25 persen menyatakan cukup setuju, 1 persen menyatakan tidak setuju dan 0 persen menyatakan sangat tidak setuju. Hal ini menunjukan responden akan merasa puas setelah membeli dan mengkonsumsi produk McDonald's.

Skor terendah dengan nilai rata-rata 3,83 pada indikator kinerja produk dibandingkan dengan produk ideal dimana dalam pernyataan tersebut responden yang menyatakan sangat setuju 24 persen, 60 persen menyatakan setuju, 28 persen menyatakan cukup setuju, 8 persen menyatakan tidak setuju dan 0 persen menyatakan sangat tidak setuju. Hal ini menunjukan bahwa tidak semua responden menganggap kinerja produk McDonald's ideal dibandingkan pesaingnya.

Tabel 7.

Deskripsi Persepsi Responden Terhadap Loyalitas Pelanggan

\begin{tabular}{|c|c|c|c|c|c|c|c|c|c|}
\hline \multirow[t]{2}{*}{ No. } & \multirow[t]{2}{*}{ Indikator } & \multicolumn{5}{|c|}{ Proporsi Persepsi Responden (\%) } & \multirow{2}{*}{$\begin{array}{l}\text { Jumlah } \\
\text { skor }\end{array}$} & \multirow{2}{*}{$\begin{array}{l}\text { Rata- } \\
\text { rata }\end{array}$} & \multirow[t]{2}{*}{ Ket } \\
\hline & & 1 & 2 & 3 & 4 & 5 & & & \\
\hline 1 & $\begin{array}{l}\text { Melakukan pembelian } \\
\text { berulang }\end{array}$ & 0 & 3 & 34 & 55 & 28 & 468 & 3,90 & Loyal \\
\hline 2 & $\begin{array}{l}\text { Membeli antar lini } \\
\text { produk }\end{array}$ & 2 & 14 & 28 & 58 & 18 & 436 & 3,63 & Loyal \\
\hline 3 & $\begin{array}{l}\text { Mereferensikan } \\
\text { kepada orang lain }\end{array}$ & 1 & 9 & 37 & 55 & 18 & 440 & 3,67 & Loyal \\
\hline 4 & $\begin{array}{l}\text { Menunjukan } \\
\text { kekebalan terhadap } \\
\text { tarikan dari pesaing }\end{array}$ & 2 & 18 & 40 & 45 & 15 & 413 & 3,44 & Loyal \\
\hline 5 & $\begin{array}{l}\text { Komitmen pada } \\
\text { produk }\end{array}$ & 1 & 19 & 34 & 45 & 21 & 426 & 3,55 & Loyal \\
\hline Rata & rata keseluruhan variabe & $\mathrm{Ke}$ & an pe & ggan & & & 2183 & 3,64 & Loyal \\
\hline
\end{tabular}

Hasil perhitungan pada Tabel 7 menunjukkan bahwa secara keseluruhan pada variabel loyalitas pelanggan dengan rata-rata total sebesar 3,64 persen dan masuk dalam kriteria baik. Hal ini menunjukan responden loyal terhadap produk McDonald's. Variabel loyalitas pelanggan yang diukur menggunakan 5 indikator 
dengan menunjukan nilai rata-rata tertinggi pada indikator melakukan pembelian berulang mencapai nilai rata-rata sebesar 3,90 persen hal ini menunjukan responden akan membeli kembali produk McDonald's.

Skor terendah pada indikator menunjukan kekebalan terhadap tarikan dari pesaing pada pernyataan tersebut sebanyak 15 persen menyatakan sangat setuju, 45 persen menyatakan setuju, 40 persen menyatakan cukup setuju, 18 persen menyatakan tidak setuju, 2 persen menyatakan sangat tidak setuju. Hal ini menunjukan tidak semua responden kebal terhadap tarikan pesaing.

Pengujian terhadap hipotesis yang diajukan dalam penelitian ini menggunakan metode analisis jalur (path analysis). Analisis jalur adalah perluasan dari analisis regresi linier berganda untuk menguji hubungan kausalitas antara dua atau lebih variabel. Hasil perhitungan koefisien path pengaruh harga terhadap kepuasan pelanggan (persamaan regresi 1) dalam penelitian ini di rangkum dalam Tabel 8 berikut:

Tabel 8.

Hasil Analisis Jalur Persamaan Regresi 1

\begin{tabular}{|c|c|c|c|c|c|}
\hline \multirow{2}{*}{ Model } & \multicolumn{2}{|c|}{$\begin{array}{l}\text { Unstandardized } \\
\text { Coefficients }\end{array}$} & \multirow{2}{*}{$\begin{array}{c}\begin{array}{c}\text { Standardized } \\
\text { Coefficients }\end{array} \\
\text { Beta } \\
\end{array}$} & \multirow{2}{*}{$\mathrm{T}$} & \multirow{2}{*}{ Sig. } \\
\hline & B & Std.Error & & & \\
\hline (Constant) & 3,151 & 0,861 & & 3,659 & 0,000 \\
\hline Persepsi Harga & 0,553 & 0,055 & 0,680 & 10.079 & 0,000 \\
\hline $\begin{array}{ll}\mathrm{R}_{1} & : 0,463 \\
\text { F Statistik }: & 101,594 \\
\text { Sig F } & : 0,000\end{array}$ & & & & & \\
\hline
\end{tabular}

Tabel 8 menunjukan nilai $\beta_{1}$ sebesar 0,680 memiliki arti bahwa persepsi harga berpengaruh signifikan terhadap kepuasan pelangan, dengan kata lain jika faktor harga yang terjangkau pelanggan, harga sesuai dengan kualitas, harga yang ditawarkan wajar, dan harga sesuai dengan informasi yang diberikan akan 
I Putu Eka Astra Prasad, Peran Kepuasan Pelanggan Memediasi Pengaruh Persepsi...

mengakibatkan peningkatan pada kepuasan pelanggan di McDonald's sebesar 0,680 .

Tabel 9.

Hasil Analisis Jalur Persamaan Regresi 2

\begin{tabular}{|c|c|c|c|c|c|}
\hline \multirow[t]{2}{*}{ Model } & \multicolumn{2}{|c|}{$\begin{array}{c}\text { Unstandardized } \\
\text { Coefficients }\end{array}$} & \multirow{2}{*}{$\begin{array}{c}\text { Standardized } \\
\text { Coefficients }\end{array}$} & \multirow{2}{*}{$\mathrm{T}$} & \multirow{2}{*}{ Sig. } \\
\hline & $\mathrm{B}$ & Std.Error & & & \\
\hline 1 (Constant) & $-1,873$ & 1,733 & & $-1,081$ & 0,282 \\
\hline Persepsi Harga & 0,412 & 0,143 & 0,243 & 2,885 & 0,005 \\
\hline Kepuasan Pelanggan & 1,164 & 0,176 & 0,558 & 6,633 & 0,000 \\
\hline
\end{tabular}

$R_{2} \quad: 0,555$

F Statistik : 72,897

Sig F $: 0,000$

Sumber :data diolah, 2018

Tabel 9 menunjukan nilai $\beta_{2}$ adalah sebesar 0,243 memiliki arti bahwa persepsi harga berpengaruh signifikan terhadap loyalitas pelanggan, dengan kata lain faktor persepsi harga meningkat maka akan mengakibatkan peningkatan pada loyalitas pelanggan di McDonald's sebesar 0,243. Nilai $\beta_{3}$ adalah sebesar 0,558 memiliki arti bahwa kepuasan pelanggan berpengaruh signifikan terhadap loyalitas pelanggan, dengan kata lain jika faktor kepuasan pelanggan meningkat maka akan mengakibatkan peningkatan pada loyalitas pelanggan di McDonald's sebesar 0,558 .

Nilai standar eror dari hasil uji analisis jalur 1 dan 2 dalam penelitian ini dapat di hitung dengan rumus sebagai berikut :

$$
\begin{aligned}
& \left(\varepsilon_{1}=\sqrt{1}-R^{2}\right)\left(\varepsilon_{2}=\sqrt{1}-R^{2}\right) \\
& \varepsilon_{1}=\sqrt{1}-0,463=0,732 \\
& \varepsilon_{2}=\sqrt{1}-0,555=0,667
\end{aligned}
$$


Berdasarkan perhitungan pengaruh error (e), didapatkan hasil pengaruh error (a) sebesar 0,732 dan pengaruh error (b) sebesar 0,667. Hasil koefisien determinasi total adalah sebagai berikut :

$$
\begin{aligned}
R^{2} \mathrm{~m} & =1-\left(a^{2}\right)\left(b^{2}\right) \\
& =1-(0,732)^{2}(0,667)^{2} \\
& =1-(0,535)(0,444) \\
& =1-0,237=0,76
\end{aligned}
$$

Nilai Determinasi total sebesar 0,76 mempunyai arti bahwa 76 persen variasi loyalitas pelanggan dipengaruhi oleh variabel persepsi harga dan variasi kepuasan pelanggan, sedangkan sisanya sebesar 24 persen dijelaskan oleh faktor lain yang tidak dimasukan ke dalam model.

Berdasarkan model diagram jalur pada gambar 2, dapat diketahui bahwa besarnya pengaruh langsung persepsi harga terhadap loyalitas pelanggan $\left(\beta_{2}\right)$ sebesar 0,243 dengan nilai signifikansi 0,005 (signifikan), kemudian pengaruh persepsi harga terhadap kepuasan pelanggan $\left(\beta_{1}\right)$ sebesar 0,680 dengan nilai signifikansi 0,000 (signifikan), dan pengaruh kepuasan pelanggan terhadap loyalitas pelanggan $\left(\beta_{3}\right)$ sebesar 0,558 dengan nilai signifikansi 0,000 (signifikan). Oleh karena nilai $\beta_{1}$ dan $\beta_{3}$ signifikan, serta nilai $\beta_{2}$ juga signifikan, dimana koefisien dari pengaruh langsung persepsi harga terhadap loyalitas pelanggan $\left(\beta_{2}\right)$ sebesar 0,243 lebih kecil dari pengaruh tidak langsung persepsi harga terhadap loyalitas pelanggan $(0,680 \times 0,558=0,379)$, maka kepuasan pelanggan dikatakan sebagai variabel mediasi sebagian (partial mediation). 
I Putu Eka Astra Prasad, Peran Kepuasan Pelanggan Memediasi Pengaruh Persepsi...

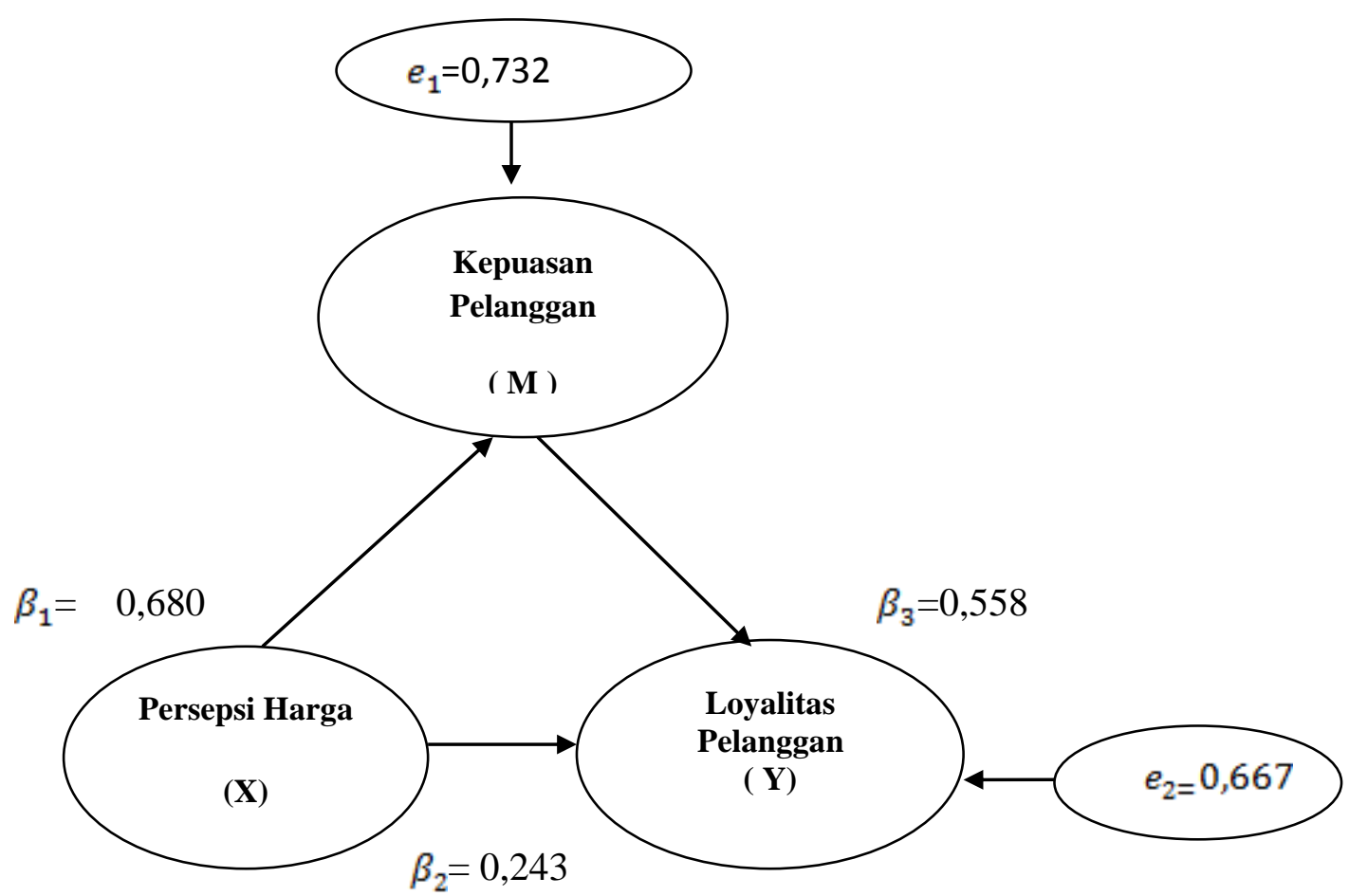

Gambar 2. Validasi Model Diagram jalur Akhir

Sumber: Data primer diolah, 2018

Berdasarkan Model diagram jalur pada gambar 2, dapat dihitumg besarnya pengaruh langsung dan tidak langsung serta pengaruh keseluruhan antar variabeL.

Tabel 10.

Pengaruh Langsung dan Pengaruh Tidak Langsung

\begin{tabular}{lccc}
\hline Pengaruh Variabel & $\begin{array}{c}\text { Pengaruh } \\
\text { Langsung }\end{array}$ & $\begin{array}{c}\text { Pengaruh Tidak } \\
\text { Langsung melalui } \\
\text { kepuasan Pelanggan } \\
(\mathbf{M}) \text { (P1XP3) }\end{array}$ & Pengaruh total \\
\hline $\mathrm{X} \longrightarrow \mathrm{M}$ & 0,680 & - & 0,680 \\
$\mathrm{X} \longrightarrow \mathrm{Y}$ & 0,243 & 0,379 & 0,622 \\
$\mathrm{M} \longrightarrow \mathrm{Y}$ & 0,558 & - & 0,558 \\
\hline Sumber: Data primer diolah, 2018 & &
\end{tabular}

Hasil pada tabel 10 menunjuKkan bahwa pengaruh langsung variabel persepsi harga terhadap kepuasan pelanggan sebesar 0,680 dan antara persepsi harga terhadap loyalitas pelanggan memiliki nilai koefisien beta sebesar 0,243 namun pengaruh tidak langsung yang dimediasi oleh kepuasan pelanggan menunjukan 
nilai koefisien beta sebesar 0,379 . Dengan dilai pengaruh total sebesar 0,622 dan yang terakhir nilai pengaruh langsung antara kepuasan pelanggan dan loyalitas pelanggan sebesar 0,558 .

Alat analisis yang digunakan untuk menguji signifikansi dari hubungan tidak langsung antara variabel persepsi harga dengan variabel loyalitas pelanggan yang dimediasi oleh variabel kepuasan pelanggan, dalam penelitian ini menggunakan rumus Sobel, dengan perhitungan sebagai berikut.

$$
\begin{aligned}
& Z=\frac{a b}{\sqrt{b^{2} s_{a}^{2}+a^{2} s_{b}^{2}+s_{a}^{2} s_{b}^{2}}} \\
& Z=\frac{(0,68) \cdot(0,558)}{\sqrt{(0,558)^{2}(0,055)^{2}+(0,68)^{2}(0,176)^{2}+(0,055)^{2}(0,176)^{2}}} \\
& Z=\frac{0,3794}{0,0154} \\
& Z=3,061
\end{aligned}
$$

Hasil uji Sobel menunjukan bahwa nilai $\mathrm{Z}$ sebesar 3,061 yang artinya $\geq$ dari nilai yang ditentukan 1,96 dengan tingkat signifikansi 0,000 yang berarti variabel mediator yakni kepuasan pelanggan dinilai secara signifikan memediasi pengaruh antara persepsi harga terhadap loyalitas pelanggan secara parsial.

\section{Pengaruh persepsi harga terhadap kepuasan pelanggan}

Pengujian hipotesis pada pengaruh persepsi harga terhadap kepuasan pelanggan McDonald's di Kota Denpasar dengan koefisien beta sebesar 0,680 yang menunjukan bahwa persepsi harga berpengaruh signifikan terhadap kepuasan pelanggan. Hal tersebut berarti dengan harga yang terjangkau, harga 
I Putu Eka Astra Prasad, Peran Kepuasan Pelanggan Memediasi Pengaruh Persepsi...

yang wajar, harga sesuai dengan informasi dan harga yang sesuai dengan kualitas maka akan semakin meningkatkan kepuasan pelanggan. Hasil penelitian ini didukung oleh penelitian sebelumnya yang dilakukan oleh Fata dkk. (2015), Wijaya dan Nurcaya (2017) dan Consuegra et al. (2007) yang menyatakan bahwa harga berpengaruh signifikan terhadap kepuasan pelanggan.

\section{Pengaruh persepsi harga terhadap loyalitas pelanggan}

Pengujian hipotesis pada pengaruh persepsi harga terhadap loyalitas pelanggan dengan koefisien beta sebesar 0,243 yang menunjukan bahwa persepsi harga berpengaruh signifikan terhadap loyalitas pelanggan. Hal tersebut berarti dengan harga yang terjangkau, harga yang wajar, harga sesuai dengan informasi dan harga yang sesuai dengan kualitas maka akan semakin meningkatkan loyalitas pelanggan tersebut. Hasil penelitian ini didukung oleh penelitian sebelumnya yang dilakukan oleh Suwarni dan Mayasari (2011), Aliasadi et al. (2012) dan Tomida dan Budhi (2016) yang menyatakan bahwa harga berpengaruh signifikan terhadap loyalitas pelanggan.

\section{Pengaruh kepuasan pelanggan terhadap loyalitas pelanggan}

Pengujian hipotesis pada pengaruh kepuasan pelanggan terhadap loyalitas pelanggan dengan koefisien beta sebesar 0,558 yang menunjukan bahwa kepuasan pelanggan berpengaruh signifikan terhadap loyalitas pelanggan. Hal tersebut dengan adanya kepuasan keseluruhan, tingkat kinerja produk sesuai dengan pengharapan dan kinerja produk yang idela diabndingkan pesaingnya maka akan 
semakin meningkatkan loyalitas dari pelanggan. Hasil penelitian ini didukung oleh penelitian sebelumnya yang dilakukan oleh Dimyati (2015), Kaura Vinita et al. (2015) dan Colognesi dan Alit (2015) yang menyatakan bahwa tingkat kepuasan pelanggan berpengaruh signifikan terhadap loyalitas pelanggan,.

Peran mediasi kepuasan pelanggan dalam menjelaskan pengaruh persepsi harga terhadap loyalitas pelanggan

Pengujian hipotesis pada peran mediasi kepuasan pelanggan dalam menjelaskan pengaruh persepsi harga terhadap loyalitas pelanggan dengan menggunakan Uji Sobel atau Sobel Test membuktikan bahwa peran kepuasan pelanggan mampu memediasi pengaruh persepsi harga terhadap loyalitas pelanggan dengan hasil $\mathrm{Z}=3,061 \geq 1,96$. Hasil penelitian ini didukung oleh penelitian sebelumnya yang dilakukan oleh Putra dan Edy (2012), Kurniasih (2012) dan Darmawan dan Ekawati (2017) yang menyatakan bahwa kepuasan pelanggan berperan sebagai variabel mediasi antara persepsi harga dan loyalitas pelanggan.

\section{SIMPULAN DAN SARAN}

Simpulan yang dapat diberikan berdasarkan hasil penelitian yang telah dilakukan yaitu 1) Persepsi harga berpengaruh signifikan terhadap kepuasan pelanggan produk McDonald's di Kota Denpasar. Hal ini berarti bahwa,jika harga yang ditetapkan McDonald's sudah sesuai maka akan meningkatkan kepuasan pelanggan. 2) Persepsi harga berpengaruh signifikan terhadap loyalitas pelanggan produk McDonald's di Kota Denpasar. Hal ini berarti bahwa, jika harga yang 
I Putu Eka Astra Prasad, Peran Kepuasan Pelanggan Memediasi Pengaruh Persepsi...

ditawarkan McDonald's sudah sesuai dengan produk yang diterima pelanggan maka kepuasan yang dirasakan pelanggan akan semakin tinggi dan tentunya semakin loyal pelanggan tersebut terhadap produk McDonald's. 3) Kepuasan pelanggan berpengaruh signifikan terhadap loyalitas pelanggan produk McDonald's di Kota Denpasar. Hal ini berarti jika semakin tinggi tingkat kepuasan pelanggan maka akan semakin tinggi loyalitas pelanggan terhadap produk McDonald's di Kota Denpasar. 4) Kepuasan pelanggan mampu memediasi pengaruh persepsi harga terhadap loyalitas pelanggan produk McDonald's di Kota Denpasar.

Berdasarkan hasil dan kesimpulan dalam penelitian ini, maka saran yang dapat diberikan antara lain pihak manajemen McDonald's perlu memperhatikan harga McDonald's kedepannya agar memberikan harga yang wajar misalnya harga yang sesuai dengan kualitas yang ditawarkan. Selain itu, pihak manajemen McDonald's perlu memperhatikan kinerja produknya agar memiliki produk yang ideal dibandingkan pesaingnya yaitu dengan memperhatikan kualitas yang sesuai dengan harganya agar dapat membuat para pelanggannya menjadi puas. Kemudian pihak manajemen McDonald's juga perlu meningkatkan kualitas dan harga yang bersaing untuk kepuasan para pelanggan agar dapat meningkatkan loyalitas para pelanggan produk McDonald's agar pelanggan kebal terhadap tarikan pesaingnya.

Bagi peneliti selanjutnya, diharapkan dapat memperluas ruang lingkup penelitian dengan pelanggan yang tersebar diberbagai wilayah, baik skala regional maupun nasional dengan produk yang lebih dikenal masyarakat luas. Penelitian 
selanjutnya juga dapat mengubah objek penelitiannya. Dalam penelitian dimasa mendatang juga perlu dipertimbangkan untuk menggunakan variabel lain sehingga dapat memperkaya informasi yang diperoleh.

\section{REFERENSI}

Aaker, David Allen. 2002. Building Strong Brands. London: The Bath Press

Aditya, Kadek Yoga dan Wardana, I Made. 2017. Peran Brand Equity dalam Memediasi Pengaruh Word Of Mouth terhadap Niat Beli. E-Jurnal Manajemen Unud. 6 (2). Hal. 830 - 856

Ambarwati, Miki; Sunarti dan Mawardi, Mukhammad Kholid. 2015. Pengaruh Citra Merek terhadap Minat Beli (Survei Pada Mahasiswa Universitas Brawijaya yang Menggunakan Pasta Gigi Pepsodent). Jurnal Administrasi Bisnis. 25 (1). Hal. 1 -

Bataineh, Abdallah Q. 2015. The Impact of Perceived e-WOM on Purchase Intention: The Mediating Role of Corporate Image. International Journal of Marketing Studies. 7 (1). PP. 126 - 137

Bambauer Sachse, Salke and Mangold, Sabrina. 2011. Brand Equity Dilution Through Negative Online Word-of-Mouth Communication. Journal of Retailing and Consumer Services. 18. PP. $38-45$

Chao, Reng Feng and Liao, Ping Chu. 2016. The Impact of Brand Image and Discounted Price on Purchase Intention in Outlet Mall: Consumer Attitude as Mediator. The Journal of Global Business Management. 12 (2). PP. 119 $-128$

Charo, Naimatullah; Sharma, Pershant; Shaikh, Saadullah; Haseeb, Abdul and Sufya, Muhammad Zohaib. 2015. Determining The Impact of E-wom on Brand Image and Purchase Intention Through Adoption of Online Opinions. International Journal of Humanities and Management Sciences. 3 (1). PP. $41-46$

Dewa, Chriswardana Bayu. 2015. Pengaruh Country of Origin Produk Televisi LG Terhadap Niat Beli Konsumen dengan Ekuitas Merek Sebagai Variabel Pemediasi. Jurnal Bianglala Informatika. 3 (1). Hal. 74 - 82 
I Putu Eka Astra Prasad, Peran Kepuasan Pelanggan Memediasi Pengaruh Persepsi...

Dwi Putranti, Honorata Ratnawati dan Pradana, Denny FX. Electronic Word of Mouth (E-WOM), Kepuasan Konsumen dan Pengaruh Langsung dan Tak Langsung Terhadap Minat Beli Konsumen (Studi Pada Mahasiswa FEB UNTAG di Semarang). Media Ekonomi dan Manajemen. 30 (1). Hal. 101 $-113$

Elseidi, Reham I and El Baz, Dina. 2016. Electronic Word of Mouth Effects on Consumers' Brand Attitudes, Brand Image and Purchase Intention: an Empirical Study in Egypt. The Business and Management Review. 7 (5). PP. $268-27$

Heruwati, Eni. 2010. Pengaruh Kredibilitas, Daya Tarik, dan Keahlian Celebrity Endorser terhadap Keputusan Pembelian Sepeda Motor Yamaha Mio. Skripsi Fakultas Ekonomi Universitas Diponegoro. Semarang.

Hyun, Sunghyup Sean and Kim, Wansoo. 2011. Dimensions of Brand Equity in the Chain Restaurant Industry. Cornell Hospitality Quarterly. 52 (4). PP. $429-437$

Jaafar, Siti Nurafifah; Lalp, Pan Ein and Naba, Mohaini Mohamed. 2013. Consumers Perceptions, Attitudes and Purchase Intention Towards Private Label Food Products in Malaysia. Asian Journal of Business and Management Sciences. 2 (8). PP. 73 - 90

Jalilvand, Mohammad Reza and Samiei, Neda. 2012. The Effect of Electronic Word of Mouth on Brand Image and Purchase Intention an Empirical Study in The Automobile Industry in Iran. Marketing Intelligence and Planning. 30 (4). PP. 460 - 476

Kartika, Cherry dan Piranti, Dwi. 2015. Pengaruh Electronic Word of Mouth (eWOM) Twitter @batikair Terhadap Brand Image. Jurnal Visi Komunikasi. 14 (1). Hal 104 - 116

Lin, Chinho; Wu, Yi Shuang and Victor Chen, Jeng Chun. 2013. Electronic Word-of-Mouth: The Moderating Roles of Product Involvement and Brand Image. International Conference on Technology Innovation and Industrial Management. Phuket, Thailand. PP. $29-47$

LoveLock, Christoper; Wirtz, Jochen and Mussry, Jacky. 2010. Pemasaran Jasa : Manusia, Teknologi, Strategi. Edisi ke 7. Jakarta : Erlangga.

Mowen, John C. and Minor, Michael. 2007. Perilaku Konsumen. Edisi Kedelapan. Jilid 1. Jakarta: PT Gramedia Erlangga. 
Rangkuti, F. 2002. Measuring Customer Satisfaction Teknik Mengukur dan Strategi Meningkatkan Kepuasan Pelanggan dan Analisis Kasus PLN-JP. PT. Gramedia Pustaka Utama, Jakarta.

Sa'ait, Noraini; Kanyan, Agnes and Nazrin, Mohamad Fitri. 2016. The Effect of $\mathrm{E}-\mathrm{WOM}$ on Customer Purchase Intention. International Academic Research Journal of Social Science. 2 (1). PP. $73-8$

Semuel, Hatane dan Lianto, Adi Suryanata. 2014. Analisis e-WOM, Brand Image, Brand Trust dan Minat Beli Produk Smartphone di Surabaya. Jurnal Manajemen Pemasaran. 8 (2). Hal 47 - 54

Setiawan, Putu Yudi; Troena, Eka Afnan; Armanu and Noermijati. 2014. The Effect of e-WOM on Destination Image, Satisfaction and Loyalty. International Journal of Business and Management Invention. 3 (1). PP. $22-29$

Shahrinaz, Irwan; Kusuma, Jati; Yacob, Yusman; Abdul Rahman, Dayang Hummida Abang and Mahdi, Ahmad Faisal. 2016. Relationship and Impact of E-WOM and Brand Image Towards Purchase Intention of Smartphone. Journal of Scientific Research and Development. 3 (5). PP. $117-124$

Sugiyono. 2013. Metode Penelitian Bisnis. Cetakan ke 17. Bandung: CV Alfabeta.

Sutisna. 2001. Perilaku Konsumen dan Komunikasi Pemasaran. Bandung: PT. Remaja Rosdakarya.

Wijaya, Finna Anastasia dan Sugiharto, Sugiono. 2015. Pengaruh Elektronik Word of Mouth dan Brand Image terhadap Purchase Intention pada Konsumen Smartphone Samsung yang Berbasis Android. Jurnal Manajemen Pemasaran. 9 (1). Hal. 16 - 22 